Review Article

\title{
The Antiviral Roles of Hydrogen Sulfide by Blocking the Interaction between SARS-CoV-2 and Its Potential Cell Surface Receptors
}

\author{
Jing Dai $\mathbb{D}^{1},{ }^{1}$ Xu Teng $\mathbb{D}^{2}$, Sheng Jin $\mathbb{D}^{2}, 2$ and Yuming $\mathrm{Wu} \mathbb{D}^{2,3,4}$ \\ ${ }^{1}$ Department of Clinical Diagnostics, Hebei Medical University, Hebei 050017, China \\ ${ }^{2}$ Department of Physiology, Hebei Medical University, Hebei 050017, China \\ ${ }^{3}$ Hebei Collaborative Innovation Center for Cardio-Cerebrovascular Disease, Hebei 050017, China \\ ${ }^{4}$ Key Laboratory of Vascular Medicine of Hebei Province, Hebei 050017, China
}

Correspondence should be addressed to Sheng Jin; jinshengsheng@126.com and Yuming Wu; wuyum@yahoo.com

Received 10 July 2021; Accepted 18 August 2021; Published 6 September 2021

Academic Editor: Vladimir Jakovljevic

Copyright ( 2021 Jing Dai et al. This is an open access article distributed under the Creative Commons Attribution License, which permits unrestricted use, distribution, and reproduction in any medium, provided the original work is properly cited.

The ongoing coronavirus disease 2019 (COVID-19) pandemic caused by severe acute respiratory syndrome coronavirus 2 (SARS-CoV-2) is posing a great threat to the global economy and public health security. Together with the acknowledged angiotensin-converting enzyme 2, glucose-regulated protein 78, transferrin receptor, AXL, kidney injury molecule-1, and neuropilin 1 are also identified as potential receptors to mediate SARS-CoV-2 infection. Therefore, how to inhibit or delay the binding of SARS-CoV-2 with the abovementioned receptors is a key step for the prevention and treatment of COVID19. As the third gasotransmitter, hydrogen sulfide $\left(\mathrm{H}_{2} \mathrm{~S}\right)$ plays an important role in many physiological and pathophysiological processes. Recently, survivors were reported to have significantly higher $\mathrm{H}_{2} \mathrm{~S}$ levels in COVID-19 patients, and mortality was significantly greater among patients with decreased $\mathrm{H}_{2} \mathrm{~S}$ levels. Considering that the beneficial role of $\mathrm{H}_{2} \mathrm{~S}$ against COVID-19 and COVID-19-induced comorbidities and multiorgan damage has been well-examined and reported in some excellent reviews, this review will discuss the recent findings on the potential receptors of SARS-CoV-2 and how $\mathrm{H}_{2} \mathrm{~S}$ modulates the above receptors, in turn blocking SARS-CoV-2 entry into host cells.

\section{Introduction}

The ongoing coronavirus disease 2019 (COVID-19) pandemic has now spread worldwide to more than 200 countries/regions and has caused over 180 million infections, and over 4 million deaths globally (as of 10 July 2021), which continues to rise rapidly. It is posing a great threat to the global economy and public health security. The current pandemic is caused by the novel severe acute respiratory syndrome coronavirus 2 (SARS-CoV-2), a lipid-enveloped positive-sense RNA virus belonging to the $\beta$-coronavirus genus. Similar to other $\beta$-coronaviruses, spike (S) protein mediates attachment and membrane fusion of virus particles with target cells in SARSCoV-2 infection [1]. The S protein is a typical type I fusion protein and is composed of two functional subunits: S1, which contains the receptor binding domain (RBD) to mediate receptor binding, and S2, which contains the transmembrane domain to mediate virus-cell fusion [2]. Together with the acknowledged angiotensin-converting enzyme 2 (ACE2), [3] glucose-regulated protein 78 (GRP78), [4] transferrin receptor (TFR), [5] AXL, [6] kidney injury molecule-1 (KIM-1) [7], and neuropilin 1 (NRP1) [8] are identified as additional potential receptors to mediate SARS-CoV-2 infection. The first step of SARS-CoV-2 infection in humans is the binding of RBD in the S1 subunit to the host's cell surface receptors, which plays a decisive role in the invasion and spread of viruses, and, in turn, affects the clinical symptoms of patients. Therefore, how to inhibit or delay the binding of RBD with the abovementioned receptors is a key step for the prevention and treatment of COVID-19. 
For a long time, hydrogen sulfide $\left(\mathrm{H}_{2} \mathrm{~S}\right)$ was known as a poisonous gas to life and the environment. However, since the pioneering work by Abe and Kimura in which it was reported as a neuromodulator, $\mathrm{H}_{2} \mathrm{~S}$ has been recognized as the third gasotransmitter akin to nitric oxide and carbon monoxide [9]. In biologic systems, $\mathrm{H}_{2} \mathrm{~S}$ is endogenously synthesized by three enzymes, namely, cystathionine $\gamma$ lyase (CSE), cystathionine $\beta$-synthase (CBS), and 3mercaptopyruvate sulfurtransferase (3-MST) and elicits its effect through four distinct pathways: (1) scavenging reactive oxygen species (ROS); (2) posttranslational modification, termed S-sulfhydration or persulfidation, on protein cysteine residues; (3) binding of metalloprotein centers; and (4) interaction with inter- or intramolecular disulfide bonds. [10-12] It is becoming increasingly clear that $\mathrm{H}_{2} \mathrm{~S}$ plays an important role in many physiological processes, and disturbances of the endogenous $\mathrm{H}_{2} \mathrm{~S}$ production are associated with the onset of several diseases, such as hypertension, diabetes, cancer, and viral infection. [13-15] Recently, Renieris et al. found that survivors had significantly higher $\mathrm{H}_{2} \mathrm{~S}$ levels in COVID-19 patients and mortality was significantly greater among patients with a decrease of $\mathrm{H}_{2} \mathrm{~S}$ levels. [16] Combined application of $\mathrm{N}$-acetylcysteine, a potential $\mathrm{H}_{2} \mathrm{~S}$-releasing donor, improved the symptoms in COVID-19 patients [17]. Furthermore, a beneficial role of $\mathrm{H}_{2} \mathrm{~S}$ against COVID-19 and COVID-19-induced comorbidities and multiorgan damage had been well examined and reported in some excellent reviews $[18,19]$. Here, this review will discuss the recent findings on the potential receptors of SARS-CoV-2 and how $\mathrm{H}_{2} \mathrm{~S}$ modulates the abovementioned receptors, in turn blocking SARS-CoV-2 entry into host cells.

\section{Organ Damage of the SARS-CoV-2 and the Protective Effect of $\mathrm{H}_{2} \mathrm{~S}$}

Similar to other coronaviruses, direct organ damage will be induced by the SARS-CoV-2 replication once it has invaded the host cell. [20-22] Then, it also can induce organ damage indirectly by the systemic inflammatory response (also called as cytokine storm) [23], endothelial dysfunction, [24] hypoxia, [25] and sympathetic overactivation. [26] Although high $\mathrm{H}_{2} \mathrm{~S}$ concentration is cytotoxic by inhibition of mitochondrial respiration, the physiological concentration of $\mathrm{H}_{2} \mathrm{~S}$ has been reported to protect multiple organs from injury by its broad spectra of bioactivities, including antiviral, alleviation of inflammation, restoration of endothelial function, inhibition of the hypoxia or ischemia injury, and normalization of sympathetic activities. [19, 27-29] Firstly, accumulated evidence has demonstrated that $\mathrm{H}_{2} \mathrm{~S}$ significantly decreased viral replication and improved lung functions in mice, while blockage of CSE activity or knockout of CSE expression increased viral replication and enhanced lung damage. [30] $\mathrm{H}_{2} \mathrm{~S}$ also upregulated ACE2 expression to reduce organ damages that were exacerbated by Ang II accumulation after ACE2 internalizaion [31]. Secondly, after being released, viral RNA, as a pathogen-associated molecular pattern, was recognized by a variety of pattern recognition receptors (PRRs) including Toll-like receptors (TLRs) in an immune cell. Then, large amounts of proinflammatory cytokines and chemokines were secreted in an unrestrained way causing a cytokine storm and serious organ damage [32]. $\mathrm{H}_{2} \mathrm{~S}$ was found to reduce the expression of TLRs to prevent TLR-mediated inflammatory response. [33] $\mathrm{H}_{2} \mathrm{~S}$ was also found to inhibit the secretion of virus-induced chemokines and cytokines by inhibiting the activation and nuclear translocation of NF- $\kappa \mathrm{B}$ and then reducing the transcription of proinflammatory genes [34]. Thirdly, Varga et al. verified that endothelial cells were directly infected by SARS-CoV-2 and caused diffuse endothelial inflammation, which induced endothelial dysfunction, thereby worsening organ damage. [35] $\mathrm{H}_{2} \mathrm{~S}$ was reported in various studies to ameliorate endothelial dysfunction in cardiovascular disorders such as hypertension, atherosclerosis, and metabolic syndrome, $[13,27]$ which would be beneficial for COVID-19 treatment. Fourthly, in addition to virus-related lung damage, macroand microvascular thrombosis induced by inflammation and endothelial dysfunction could cause tissue hypoxia and aggravate organ damage [36]. It was worthy of mentioning that $\mathrm{H}_{2} \mathrm{~S}$ has been identified as an excitatory mediator of hypoxic sensing in the carotid bodies to elicit its protective roles under hypoxic conditions. [37] $\mathrm{H}_{2} \mathrm{~S}$ was also found to attenuate ferric chloride-induced arterial thrombosis and enhance the blood flow. [38] In addition, it promoted angiogenesis and increased capillary density to limit damages in the ischemic tissues. [39] Finally, it was indicated that patients with preexisting cardiovascular diseases, including hypertension, diabetes mellitus, and ischemic heart disease, which were characterized by increased sympathetic activity, seem to have a higher risk of morbidity and mortality in COVID-19. Conversely, COVID-19 also increased sympathetic overactivation inducing organ damage. [40] The vicious circle between COVID-19 and sympathetic overactivation might exacerbate the organ damage and comorbidities. However, $\mathrm{H}_{2} \mathrm{~S}$ could break this vicious circle by inhibiting sympathetic activation in the significant central sympathetic sites [41, 42].

\section{The Potential Receptors of SARS-CoV-2 and $\mathrm{H}_{2} \mathrm{~S}$}

The virus-induced organ damage as described above is initiated by the binding of $S$ protein with the host's cell surface receptors. Here, the important entry receptors including ACE2, GRP78, TFR, AXL, KIM-1, and NRP1 have been outlined, and the possible mechanism of $\mathrm{H}_{2} \mathrm{~S}$ in blocking SARS-CoV-2 entry has been discussed (Table 1).

\section{ACE2 and $\mathrm{H}_{2} \mathrm{~S}$}

ACE2, a type I integral membrane glycoprotein composed of a single extracellular $\mathrm{N}$-terminal domain containing the active catalytic site domain, a C-terminal membrane anchor, and a HEXXH zinc-binding domain, is widely expressed in a variety of tissues and cell types, including those in the lungs, heart, kidneys, gut, and brain [86]. Known as a typical zinc metallopeptidase, ACE2 counterregulates the reninangiotensin-aldosterone system (RAAS) by converting Ang II to Ang 1-7 or Ang I to Ang 1-9, thus maintaining blood 
TABle 1: Potential host receptors and possible mechanism of $\mathrm{H}_{2} \mathrm{~S}$ in blocking SARS-CoV-2 entry.

\begin{tabular}{|c|c|c|}
\hline Potential receptors & Possible regulatory mechanism of $\mathrm{H}_{2} \mathrm{~S}$ & Key references \\
\hline ACE2 & Interaction with intramolecular disulfide bonds & {$[43-49]$} \\
\hline GRP78 & Downregulation of its expression by inhibiting the related signal pathways & [50-53] \\
\hline \multirow{2}{*}{ TFR } & Downregulation of its expression at transcriptional levels & [54-56] \\
\hline & Downregulation of its expression at posttranscriptional levels & {$[57-60]$} \\
\hline \multirow{3}{*}{ AXL } & Downregulation of its expression by S-sulfhydrating its transcription factor & {$[61,62]$} \\
\hline & Downregulation of its expression by inhibiting its transcription factor translocation & [63-65] \\
\hline & Downregulation of its expression by histone acetylation of its promoter & {$[66-68]$} \\
\hline \multirow{2}{*}{ KIM-1 } & Downregulation of its expression by reducing the phosphorylation of its transcription factor & [69-72] \\
\hline & Downregulation of its expression by reducing ROS or ERK1/2 pathway & {$[73-75]$} \\
\hline \multirow{4}{*}{ NRP1 } & Downregulation of its expression by S-sulfhydrating its transcription factor & {$[62,76]$} \\
\hline & Downregulation of its expression by inhibiting its transcription factor translocation & {$[64,65,77]$} \\
\hline & Inhibition of cytokines & {$[78-81]$} \\
\hline & Downregulation of its expression by inhibiting the related signal pathways & [82-85] \\
\hline
\end{tabular}

pressure homeostasis and fluid and salt balance. It also functions as an amino acid transporter or a functional receptor for MERS-CoV and SARS-CoV. [87] Like in SARS-CoV infections, ACE2 serves as a major entry receptor for SARS-CoV-2 in humans by binding to its $S$ protein. [88] ACE2 has a 10 - to 20 -fold higher affinity for SARS-CoV-2 $S$ than for SARS-CoV, which results in a higher SARSCoV-2 infection efficiency. [89] Recent evidence in the literature indicated that intra- and intermolecular disulfides in both ACE2 and SARS-CoV-2 S protein had an important role for the binding process, which was regulated by the thiol-disulfide balance of the extracellular environment. $[43,44]$ Using molecular dynamics simulations revealed that the reduction of all disulfides into the sulfydryl groups completely impaired the binding of the SARS-CoV-2 S protein to ACE2. When the disulfides of only ACE2 were reduced to sulfydryl groups, the binding became weaker, while the reduction of disulfides of the SARS-CoV-2 S protein had a comparatively less effect [45]. Recently, several reducing agents including $\mathrm{N}$-acetylcysteine amide and $\mathrm{L}$ ascorbic acid were reported to inhibit viral entry by the disruption of disulfides [46]. As a weak reducing agent, $\mathrm{H}_{2} \mathrm{~S}$ activated vascular endothelial growth factor receptor 2 (VEGFR2) to promote angiogenesis by breaking the Cys1045-Cys1024 disulfide bond within the receptor [47]. $\mathrm{H}_{2} \mathrm{~S}$ also targeted the Cys320/Cys529 motif and broke the disulfide bonds in $\mathrm{Kv} 4.2$ to inhibit $\mathrm{I}_{\text {to }}$ potassium channels in cardiomyocytes and regularize fatal arrhythmia in myocardial infarction [48]. Moreover, $\mathrm{H}_{2} \mathrm{~S}$ was used to break mucin disulfide bonds, making the mucus less viscous and easier to be expelled by the respiratory ciliary apparatus, facilitating the elimination of potentially harmful viruses or extraneous particle [49]. Thus, $\mathrm{H}_{2} \mathrm{~S}$ is hypothesized to exhibit antiviral activity by interfering with the combination of ACE2 and SARS-CoV-2.

\section{CS-GRP78 and $\mathrm{H}_{2} \mathrm{~S}$}

GRP78, also known as immunoglobulin heavy-chainbinding protein (BiP) or heat shock protein A5 (HSPA5), is a well-characterized endoplasmic reticulum (ER) chaperone protein whose function is to translocate nascent polypeptides across the ER membrane and facilitates the correct folding and assembly of proteins in normal cells. When misfolded proteins accumulate in the ER following ER stress, GRP78 is upregulated and plays a pivotal role in the unfolded protein response (UPR) by binding to misfolded proteins initiating the refolding or degradation mechanisms [90]. Conversely, under the ER stress, overexpressed GRP78 can escape the ER retention and translocate to the cell surface, termed cell surface CS-GRP78, where it functions as a multifunctional receptor to regulate cellular signaling, proliferation, migration, invasion, apoptosis, inflammation, and immunity [91]. CS-GRP78 is also reported to play a critical role in viral and fungal infections. Viruses including Coxsackie virus, Zika virus, dengue virus, and Borna disease virus recognize CS-GRP78 for entry or invasion into the host cells. [92] CS-GRP78 was reported to facilitate MERS-CoV entry into permissive cells by augmenting virus attachment in the presence of DPP4 [93]. Recently, a molecular dynamics study combined with molecular docking revealed the existence of H-bonds or hydrophobic contacts between GRP78 and C480-C488 of SARS-CoV-2 S protein $[4,94]$, which might be related to viral infection. A better binding was also found between GRP78 and the new UK variant of SARS-CoV-2. [95] In addition, COVID-19 patients had higher gene expression and serum concentrations of GRP78 [96]. Considering that virus invasion was associated with elevated levels of CS-GRP78 expression, inhibiting overexpressed GRP78 would be a promising strategy to reduce virus infection. $\mathrm{H}_{2} \mathrm{~S}$ has been reported to downregulate the expressions of ER stress-related proteins, including GRP78, in multiple diseases by different pathways. Our study found that the ER stress markers, including GRP78, CHOP, and active caspase-12 levels, were significantly elevated in the calcified rat aorta and $\mathrm{H}_{2} \mathrm{~S}$ alleviated vascular calcification by inhibiting ERS through the Akt signaling pathway activation [50]. In uranium-treated kidney cells, $\mathrm{H}_{2} \mathrm{~S}$ downregulated the expressions of GRP78 and CHOP and attenuated ER stress via $20 \mathrm{~S}$ proteasome involved in Akt/GSK-3 $\beta /$ Fyn-Nrf2 
signaling axis. [51] In hyperhomocysteinemia-induced cardiomyocyte injury, $\mathrm{H}_{2} \mathrm{~S}$ supplementation decreased the expressions of ER stress-associated proteins, including GRP78, while the inhibition of endogenous $\mathrm{H}_{2} \mathrm{~S}$ production further increased the expressions of those proteins [52]. $\mathrm{H}_{2} \mathrm{~S}$ was also reported to inhibit cigarette smoke-induced overexpression of ER stress-associated proteins in bronchial epithelial cells [53]. Therefore, $\mathrm{H}_{2} \mathrm{~S}$ may block the SARSCoV-2 from entering the host cells by inhibiting the ES stress and reducing the expression of CS-GRP78.

\section{TFR and $\mathrm{H}_{2} \mathrm{~S}$}

TFR is a membrane receptor playing a critical role in the maintenance of body iron homeostasis. The TFRs have two subtypes: TFR1 and TFR2. TFR1 is ubiquitously expressed at different levels on normal cells and serves as a gatekeeper regulating the cellular uptake of iron from transferrin, while TFR2 is specially expressed in hepatocytes and serves as an iron sensor [97]. TFR1 has attracted more attention than TFR 2 by having diverse functions. TFR1, also known as cluster of differentiation 71 (CD71), is a homodimeric type II transmembrane glycoprotein involved in the cellular iron uptake through a constitutive clathrin-dependent endocytosis mechanism. It is expressed at low levels in most normal cells and at greater levels in rapidly proliferating cells and energy-requiring cells owing to the increased iron requirements. So, it may play additional roles in cell growth and proliferation [98]. Given that it is a ubiquitously and abundantly expressed cell surface membrane protein, TFR1 is a vulnerable target for pathogens to initiate host cell infection. It has been documented that multiple viruses, including New World hemorrhagic arenaviruses, hepatitis C virus, and human adenoviruses, recognize and bind with the apical domain of TFR1 to enter cells without interfering with iron delivery. [99] In this way, the viruses infect rapidly proliferating and iron-acquiring cells, which can facilitate their replication. Furthermore, endocytosed TRF1 recycles back to the cell surface in a constitutive manner but is not downregulated by viruses' infection, which may cause the superinfection. [100] Recently, it was reported that TFR1 directly interacted with the S protein of SARS-CoV-2 to mediate virus entry, while it was blocked by interfering TFR-spike interaction. Furthermore, anti-TFR antibody showed the promising antiviral effects in mouse model. [5] Considering that it is another receptor for SARS-CoV-2 entry, downregulating the expression of TFR1 or preventing the translocation of TFR1 to plasma membrane may be effective strategies to prevent virus invasion. Various molecular mechanisms are involved in the regulation of its expression at both the transcriptional and posttranscriptional levels. At the transcriptional level, TFR1 gene transcription has been shown to be stimulated by the transcription factor $\mathrm{c}$ Myc. [54] However, the impact of $\mathrm{H}_{2} \mathrm{~S}$ on the c-Myc remains controversial. Zhang et al. reported that exogenous $\mathrm{H}_{2} \mathrm{~S}$ activated the ERK1/2/c-Myc pathways and restored postconditioning-mediated cardioprotection in the aged cardiomyocytes [101]. Contrastingly, Song et al. reported that $\mathrm{H}_{2} \mathrm{~S}$ donor inhibited the cell proliferation by downregulating the expression of proliferation-related proteins including cMyc. [55] Moreover, diallyl disulfide, a potential $\mathrm{H}_{2} \mathrm{~S}$ donor, decreased telomerase activity in U937 cells by reduced binding of c-Myc to their respective binding sites on the promoter. [56] At the posttranscriptional level, TFR1 expression is finely regulated in an intracellular iron-dependent manner by the iron-responsive element/iron-regulated protein (IRE/IRP) system. [57] In case of cellular iron deficiency, the two IRPs (IRP1 and IRP2) bind to the multiple IRE motifs by the $-\mathrm{SH}$ residues in the $3^{\prime}$ untranslated region of TFR1 mRNA and inhibit their degradation by a steric hindrance mechanism, thus increasing TFR1 protein expression. Conversely, in the presence of excess iron, IRP1 becomes an aconitase with the binding of a $4 \mathrm{Fe}-4 \mathrm{~S}$ cluster, while IRP2 is degraded after ubiquitination, leading to the disappearance of IRE binding activity and degradation of TFR1 mRNA. Reactive oxygen species (ROS), including superoxide anion and hydrogen peroxide, was found to promote the loss of the $4 \mathrm{Fe}-4 \mathrm{~S}$ cluster and enhance the IRE binding activity of IRP1, resulting in TFR1 translation [58]. Since it has long been assumed to be an antioxidant, $\mathrm{H}_{2} \mathrm{~S}$ may inhibit the IRP binding activity and downregulated TFR1 protein by scavenging ROS. $\mathrm{H}_{2} \mathrm{~S}$ was also reported to regulate the bioactivities of multiple proteins via $\mathrm{S}$ sulfhydration of cysteine residues, [59] so $\mathrm{H}_{2} \mathrm{~S}$ might Ssulfhydrate cysteine residues of IRP1 to prevent its IRE binding activity, thus downregulating TFR1 protein. In addition, the $\mathrm{Na}^{+} / \mathrm{H}^{+}$exchanger enhanced TFR1 translocation to the membrane of microvascular endothelial cells at the bloodbrain barrier, [60] which might be inhibited by $\mathrm{H}_{2} \mathrm{~S}$ [102].

\section{AXL and $\mathrm{H}_{2} S$}

AXL, also known as UFO, ARK, Tyro7, or JTK11, belongs to the tumor-associated macrophage (TYRO3, AXL, and MERTK) family receptor tyrosine kinases (RTKs). After binding with its ligand, growth arrest-specific protein 6 (GAS6), it leads to the activation of several downstream signaling pathways, including the Ras/Raf/MEK/ERK cascade and PI3K/Akt signaling pathways, and transduces signals from the extracellular matrix into the cytoplasm. [103] AXL has been originally detected as an unidentified transforming gene in chronic myeloid leukemia. Since then, $\mathrm{AXL}$ is found to be overexpressed in many types of cancer and is associated with therapy resistance, adverse prognosis, and worse outcome [104]. Under normal physiologic conditions, AXL is ubiquitously expressed in a wide variety of organs and cells originating from hematopoietic, epithelial, and mesenchymal sources and regulates many important physiological processes, including taming inflammation, clearing apoptotic cells, maintaining vascular integrity, and regulating cell survival, proliferation, and differentiation. Moreover, AXL has been found to be a candidate entry receptor for West Nile, Ebola, and Zika viral infections and its specific inhibitors reduced viral infectivity [105]. Most recently, Wang et al. found that AXL specifically interacted with the N-terminal domain of the spike glycoprotein in SARS-CoV-2, which colocalized mainly to the cell membrane, and it was a novel entry receptor for SARS-CoV-2 
which played an important role in promoting viral infection to the human respiratory system. [6] In line with it, gilteritinib, an AXL inhibitor for acute myeloid leukemia treatment, was recently demonstrated to possess antiviral efficacy against SARS-CoV-2 infection in Vero E6 cells [106]. After virus infection, the TLR-mediated immune network is stimulated by viral particles, and then, the consequent type I interferon (IFN) antiviral response upregulates AXL expression, [107] which further promotes virus infectivity. Huang et al. reported that $\mathrm{H}_{2} \mathrm{~S}$ downregulated TLR4, inhibited its downstream NLRP3 inflammasome activation, and alleviated high glucose-induced cardiac injury [108]. $\mathrm{H}_{2} \mathrm{~S}$ was also able to ameliorate LPS-induced inflammation through TLR4/NF- $\kappa$ B signaling pathway inhibition [109]. In addition, polysulfide donors were reported to protect the mice from lethal endotoxin shock by inhibiting TLR signaling. [110] Several transcription factors, including specificity protein 1 (Sp1) [61] and hypoxia-inducible factor $1 \alpha(\mathrm{HIF}-1 \alpha)$, [63] have been shown to directly upregulate AXL expression at transcriptional levels. $\mathrm{H}_{2} \mathrm{~S}$-mediated S-sulfhydration of the Sp1 has been shown to decrease its binding activity to the gene promoter region, thus preventing myocardial hypertrophy [62]. $\mathrm{H}_{2} \mathrm{~S}$ also suppressed HIF-1 $\alpha$ translation or activation under hypoxia $[64,65]$. Conversely, reduced $\mathrm{H}_{2} \mathrm{~S}$ levels increased the levels of HIF- $1 \alpha$ via increased ROI levels in infected CSE KO macrophages [111]. Histone acetylation can also affect AXL transcript levels. Reduced histone acetylation of the AXL promoter led to the upregulation of AXL expression that correlated with therapy resistance and adverse prognosis in some types of cancers [66]. AOAA, the inhibitor of endogenous $\mathrm{H}_{2} \mathrm{~S}$ production, has been reported to reduce histone acetylation, and $\mathrm{H}_{2} \mathrm{~S}$ donor increased $\mathrm{H} 3$ and $\mathrm{H} 4$ acetylation in LPS-treated cell [67]. $\mathrm{H}_{2} \mathrm{~S}$ also suppressed the endothelial dysfunction and prevented the occurrence of hypertension by inhibiting HDAC6 expression that removes acetyl groups from lysine residues of histone to reverse histone acetylation [68]. In addition, AXL mRNA expression is inhibited by miR-34a which has identified target sequences in the AXL $3^{\prime}$ untranslated region. [112] miR-34a expression was found to upregulate diallyl disulfide-treated MDA-MB-231 cells [113].

\section{KIM-1 and $\mathrm{H}_{2} \mathrm{~S}$}

KIM-1, also known as TIM-1, is a single-pass type I cell membrane glycoprotein with an extracellular six-cysteine immunoglobulin-like (Ig V) domain topping a domain characteristic of mucin-like O-glycosylated proteins. It is virtually undetectable in normal kidney tissues, but its expression is dramatically upregulated in the apical membrane of the proximal tubule to reduce the innate immune response and regulate the regeneration and repair of the damaged epithelial cells after acute ischemic or toxic kidney injury. However, prolonged KIM-1 expression may be maladaptive and may lead to interstitial inflammation and fibrosis in chronic kidney disease. Therefore, it is recognized as a robust and reliable biomarker for early diagnosis, prognosis, and monitoring of therapeutic effects in various kidney diseases [114]. Moreover, KIM-1 is also identified as a hepatitis A virus cell receptor 1 (HAVCR-1) that is expressed by on the surface of different epithelial cells and facilitates cellular entry of several viruses, including Ebola virus, dengue virus, West Nile virus, and hepatitis A virus, via the $\operatorname{IgV}$ domain [115]. A recent report suggested that KIM-1 was not only a biomarker for COVID-19-associated acute kidney injury (AKI) [116] but also a potential receptor for SARS-CoV-2. [7] SARS-CoV-2 was reported to directly infect the renal tubules by ACE2 and induced AKI, which is one of the most prevalent complications among hospitalized COVID-19 patients [117]. After upregulated expression induced by AKI, KIM-1 could directly bind to SARS-CoV-2 $S$ protein which was inhibited both by anti-KIM-1 antibodies and TW-37, an inhibitor of KIM-1 [118]. Another study suggested that SARS-CoV-2 RBD bind with KIM-1 and ACE2 via two distinct pockets, implicating that KIM-1 and ACE2 may synergistically mediate the invasion of SARSCoV-2 in kidney cells [119]. The above "vicious cycle" exacerbates SARS-CoV-2 infection and KIM-1 may offer a new therapeutic target that can minimize injuries due to SARS$\mathrm{CoV}$-2. It was reported that $\mathrm{H}_{2} \mathrm{~S}$ treatment downregulated KIM-1 expression in hyperglycemic condition by inhibiting $\mathrm{Ca}^{2+}$-induced mitochondrial permeability transition pore opening [120]. Dopamine decreased KIM-1 levels and preserved renal integrity during deep hypothermia and rewarming likely by maintaining the expression of renal $\mathrm{H}_{2} \mathrm{~S}$-producing enzymes and serum $\mathrm{H}_{2} \mathrm{~S}$. [121] A previous report had shown that nuclear signal transducer and activator of transcription 3 (STAT3) could bind to the KIM-1 promoter and increased its mRNA and protein levels. [69] In our study, PPG, the inhibitor of endogenous $\mathrm{H}_{2} \mathrm{~S}$ production, increased phosphorylation of STAT3 and aggravated vascular remodeling, while NaHS decreased phosphorylation of STAT3 and improved vascular remodeling [70]. The AMPK pathway might mediate the inhibition of STAT3 phosphorylation by $\mathrm{H}_{2} \mathrm{~S}$ during inflammation [71]. Recently, polysulfides were also reported to attenuate diabetic renal lesions via the inactivation of STAT3 phosphorylation/acetylation through S-sulfhydrating SIRT1. [72] In addition, the increased KIM-1 expression was also mediated by the ROS or ERK1/2 pathway, [73, 74] whereas $\mathrm{H}_{2} \mathrm{~S}$ not only attenuated ROS production but also abolished ERK1/2 activation, which possibly decreased KIM-1 expression. [75]

\section{NRP1 and $\mathrm{H}_{2} \mathrm{~S}$}

Neuropilins (NRPs) are highly conserved single-pass transmembrane glycoproteins that are expressed by a wide variety of cell types, including neurons, blood vessels, immune cells, and multiple tumor cells in mammals. To date, two homologous NRP isoforms have been identified, namely, NRP1 and NRP2, which share $44 \%$ sequence homology and have a similar domain structure. The NRPs are composed of a large extracellular domain, a transmembrane domain, and a short cytoplasmic domain that lacks enzymatic activity. Despite being devoid of an intracellular kinase domain, NRPs act predominantly as a multifunctional coreceptor to bind with various ligands including class 3 semaphorins (SEMA3s), vascular endothelial growth factor, fibroblast 
growth factor, and transforming growth factor- $\beta 1$ (TGF- $\beta 1$ ) by their well-structured extracellular part. As such, NRPs mediate a wide range of signaling pathways and play critical roles in the physiological and pathological processes, including nervous and vascular development, immune response, and tumor progression. [122] Moreover, NRPs have been shown to mediate cellular entry and infectivity of viruses such as Epstein-Barr virus (EBV), human T cell lymphotropic virus-1 (HTLV-1), and murine cytomegalovirus (MCMV) [123-125]. Recent literature has established NRP1 as a coreceptor that facilitated SARS-CoV-2 cell entry and infectivity, and NRP1 mRNA expression was elevated in SARS-CoV-2-infected cells, but not in uninfected cells from severe COVID-19 patients [126]. Studies based on X-ray crystallography and biochemical approaches also showed that the SARS-CoV-2 S proteins directly bind with extracellular domain of NRP1 by electrostatic attraction and infected human cells. [8] So NRP1 could be an ideal therapeutic target against SARS-CoV-2 infections. Although it lacks a direct study, $\mathrm{H}_{2} \mathrm{~S}$ may indirectly regulate NRP1 expression by affecting its transcription factors or some cytokines. It had been demonstrated that NRP1 was the downstream target of transcription factor Sp1 or HIF- $1 \alpha$ $[76,77]$. However, as mentioned above, $\mathrm{H}_{2} \mathrm{~S}$ inhibited the downstream protein expression by regulating these two transcription factors $[62,64,65]$. Cytokines, such as TNF- $\alpha$ and TGF- $\beta$, were reported to induce NRP1 mRNA and protein expressions, $[78,79]$ while, as indicated by the plethora of evidence, $\mathrm{H}_{2} \mathrm{~S}$ downregulated TNF- $\alpha$ and TGF- $\beta$ expressions in a variety of pathological conditions $[80,81]$. In addition, NRP1 was upregulated by $\mathrm{Wnt} / \beta$-catenin signaling and sonic hedgehog (SHH)/GLI1 signaling in mammary development and tumorigenesis [82, 83]. However, diallyl trisulfide, a $\mathrm{H}_{2} \mathrm{~S}$ donor, was found to inhibit breast cancer stem cells via suppression of the $\mathrm{Wnt} / \beta$-catenin pathway, and sulforaphane, another $\mathrm{H}_{2} \mathrm{~S}$ donor, significantly inhibited the SHH/GLI1 pathway and its downstream target gene expression to regulate self-renewal of pancreatic cancer stem cells $[84,85]$.

\section{Conclusion}

This review summarizes the potential receptors for entry of SARS-CoV-2, including GRP78, TFR, AXL, KIM-1, and NRP1, in addition to ACE2. Meanwhile, the potential mechanism by which $\mathrm{H}_{2} \mathrm{~S}$ regulates the abovementioned receptors to block the binding of SARS-CoV-2 has been discussed. Although inorganic sulfide salts ( $\mathrm{NaHS}$ and $\mathrm{Na}_{2} \mathrm{~S}$ ) have been the most widely employed in biological and preclinical studies, none of them are unlikely to be a suitable clinical option for a number of reasons, including poor water solubility, fast and uncontrollable release, and unpleasant odor. Given that it is not trivial to synthesize a clinically suitable $\mathrm{H}_{2} \mathrm{~S}$ donor in a short time, three types of potential $\mathrm{H}_{2} \mathrm{~S}$ donors or drugs should be considered to block viral entry: (1) natural $\mathrm{H}_{2} \mathrm{~S}$ donors (e.g., garlic and onions) $[127,128]$ or dietary micronutrients (e.g., L-cysteine and taurine) $[129,130]$, (2) $\mathrm{H}_{2} \mathrm{~S}$ donating derivatives of clinically used drugs that link various $\mathrm{H}_{2} \mathrm{~S}$ donating groups to clinically used drugs (e.g., ATB-346
[131] and GIC-1001 [132] which has completed phase 2 clinical trial), and (3) several clinically used drugs that have been verified to increase $\mathrm{H}_{2} \mathrm{~S}$ levels (e.g., $\alpha$-lipoic acid, [133] sodium thiosulfate, [134] zofenoprilat, [135] and $\mathrm{N}$-acetylcysteine [136]). Sodium thiosulfate has been proposed as an inhalation therapy for COVID-19, [137] and it was confirmed that the combined application of $\mathrm{N}$-acetylcysteine improved the symptoms in COVID-19 patient. [17] However, the abovementioned is just a stopgap; developing new clinically suitable $\mathrm{H}_{2} \mathrm{~S}$ donor drugs is necessary, and the clinical application of $\mathrm{H}_{2} \mathrm{~S}$-targeted therapeutics to fight against diseases that are not limited to COVID-19 should advance.

\section{Conflicts of Interest}

The authors declare that there is no conflict of interests regarding the publication of this paper.

\section{Acknowledgments}

This study was supported by the National Natural Science Foundation of China (91849120, 31871154, and 31671185), the Natural Science Foundation of Hebei Province of China (C2020206025 and H2020206417), the Key R \&D Project of Hebei Province (20277735D), and the Research Foundation for Higher Education of Hebei Province (ZD2019027).

\section{References}

[1] M. M. Hatmal, W. Alshaer, M. A. I. Al-Hatamleh et al., "Comprehensive structural and molecular comparison of spike proteins of SARS-CoV-2, SARS-CoV and MERS-CoV, and their interactions with ACE2," Cell, vol. 9, no. 12, p. 2638, 2020.

[2] Z. Ke, J. Oton, K. Qu et al., "Structures and distributions of SARS-CoV-2 spike proteins on intact virions," Nature, vol. 588, no. 7838, pp. 498-502, 2020.

[3] Q. Wang, Y. Zhang, L. Wu et al., "Structural and functional basis of SARS-CoV-2 entry by using human ACE2," Cell, vol. 181, no. 4, pp. 894-904.e9, 2020.

[4] I. M. Ibrahim, D. H. Abdelmalek, M. E. Elshahat, and A. A. Elfiky, "COVID-19 spike-host cell receptor GRP78 binding site prediction," The Journal of Infection, vol. 80, no. 5, pp. 554-562, 2020.

[5] X. P. Tang, M. L. Yang, Z. L. Duan et al., "Transferrin receptor is another receptor for SARS-CoV-2 entry," bioRxiv, 2020.

[6] S. Wang, Z. Qiu, Y. Hou et al., "AXL is a candidate receptor for SARS-CoV-2 that promotes infection of pulmonary and bronchial epithelial cells," Cell Research, vol. 31, no. 2, pp. 126-140, 2021.

[7] C. Wan and C. Zhang, "Kidney injury molecule-1: a novel entry factor for SARS-CoV-2," Journal of Molecular Cell Biology, vol. 13, no. 3, pp. 159-160, 2021.

[8] J. L. Daly, B. Simonetti, K. Klein et al., "Neuropilin-1 is a host factor for SARS-CoV-2 infection," Science, vol. 370, no. 6518, pp. 861-865, 2020.

[9] K. Abe and H. Kimura, "The possible role of hydrogen sulfide as an endogenous neuromodulator," The Journal of Neuroscience, vol. 16, no. 3, pp. 1066-1071, 1996. 
[10] A. Aroca, C. Gotor, D. C. Bassham, and L. C. Romero, "Hydrogen sulfide: from a toxic molecule to a key molecule of cell life," Antioxidants, vol. 9, no. 7, p. 621, 2020.

[11] B. Murphy, R. Bhattacharya, and P. Mukherjee, "Hydrogen sulfide signaling in mitochondria and disease," The FASEB Journal, vol. 33, no. 12, pp. 13098-13125, 2019.

[12] R. Wang, B. Tao, Q. Fan et al., "Fatty-acid receptor CD36 functions as a hydrogen sulfide-targeted receptor with its Cys333-Cys272 disulfide bond serving as a specific molecular switch to accelerate gastric cancer metastasis," eBioMedicine, vol. 45, pp. 108-123, 2019.

[13] H. J. Sun, Z. Y. Wu, X. W. Nie, and J. S. Bian, "Role of endothelial dysfunction in cardiovascular diseases: the link between inflammation and hydrogen sulfide," Frontiers in Pharmacology, vol. 10, p. 1568, 2020.

[14] X. Cao, L. Ding, Z. Z. Xie et al., “A review of hydrogen sulfide synthesis, metabolism, and measurement: is modulation of hydrogen sulfide a novel therapeutic for cancer?," Antioxidants es Redox Signaling, vol. 31, no. 1, pp. 1-38, 2019.

[15] V. K. Pal, P. Bandyopadhyay, and A. Singh, "Hydrogen sulfide in physiology and pathogenesis of bacteria and viruses," IUBMB Life, vol. 70, no. 5, pp. 393-410, 2018.

[16] G. Renieris, K. Katrini, C. Damoulari et al., "Serum hydrogen sulfide and outcome association in pneumonia by the SARS-CoV-2 coronavirus," Shock, vol. 54, no. 5, pp. 633637, 2020.

[17] Y. Liu, M. Wang, G. Luo et al., "Experience of Nacetylcysteine airway management in the successful treatment of one case of critical condition with COVID-19: a case report," Medicine (Baltimore), vol. 99, no. 42, article e22577, 2020.

[18] G. Yang, " $\mathrm{H}_{2} \mathrm{~S}$ as a potential defense against COVID-19?," American Journal of Physiology. Cell Physiology, vol. 319, no. 2, pp. C244-C249, 2020.

[19] V. Citi, A. Martelli, V. Brancaleone et al., “Anti-inflammatory and antiviral roles of hydrogen sulfide: rationale for considering H2S donors in COVID-19 therapy," British Journal of Pharmacology, vol. 177, no. 21, pp. 4931-4941, 2020.

[20] D. Lindner, A. Fitzek, H. Bräuninger et al., "Association of cardiac infection with SARS-CoV-2 in confirmed COVID19 autopsy cases," JAMA Cardiology, vol. 5, no. 11, pp. 1281-1285, 2020.

[21] C. Ronco, T. Reis, and F. Husain-Syed, "Management of acute kidney injury in patients with COVID-19," The Lancet Respiratory Medicine, vol. 8, no. 7, pp. 738-742, 2020.

[22] Y. Yachou, A. El Idrissi, V. Belapasov, and B. S. Ait, "Neuroinvasion, neurotropic, and neuroinflammatory events of SARS-CoV-2: understanding the neurological manifestations in COVID-19 patients," Neurological Sciences, vol. 41, no. 10, pp. 2657-2669, 2020.

[23] N. Mangalmurti and C. A. Hunter, "Cytokine storms: understanding COVID-19,” Immunity, vol. 53, no. 1, pp. 19-25, 2020.

[24] P. Libby and T. Lüscher, "COVID-19 is, in the end, an endothelial disease," European Heart Journal, vol. 41, no. 32, pp. 3038-3044, 2020.

[25] Y. Liu, J. Lv, J. Liu et al., "Mucus production stimulated by IFN-AhR signaling triggers hypoxia of COVID-19," Cell Research, vol. 30, no. 12, pp. 1078-1087, 2020.

[26] S. Jin, J. Dai, X. Teng, and Y. M. Wu, “Adverse effects of sympathetic activation should not be neglected during the coro- navirus disease 2019 pandemic," Chinese Medical Journal, vol. 134, no. 4, pp. 413-414, 2020.

[27] V. Citi, A. Martelli, E. Gorica, S. Brogi, L. Testai, and V. Calderone, "Role of hydrogen sulfide in endothelial dysfunction: pathophysiology and therapeutic approaches," Journal of Advanced Research, vol. 27, pp. 99-113, 2020.

[28] A. R. Jensen, N. A. Drucker, S. Khaneki et al., "Hydrogen sulfide: a potential novel therapy for the treatment of ischemia," Shock, vol. 48, no. 5, pp. 511-524, 2017.

[29] X. Feng, Q. Guo, H. Xue, X. Duan, S. Jin, and Y. Wu, "Hydrogen sulfide attenuated angiotensin II-induced sympathetic excitation in offspring of renovascular hypertensive rats," Frontiers in Pharmacology, vol. 11, article 565726, 2020.

[30] T. Ivanciuc, E. Sbrana, M. Ansar et al., "Hydrogen sulfide is an antiviral and antiinflammatory endogenous gasotransmitter in the airways. Role in respiratory syncytial virus infection," American Journal of Respiratory Cell and Molecular Biology, vol. 55, no. 5, pp. 684-696, 2016.

[31] Y. Lin, H. Zeng, L. Gao, T. Gu, C. Wang, and H. Zhang, "Hydrogen sulfide attenuates atherosclerosis in a partially ligated carotid artery mouse model via regulating angiotensin converting enzyme 2 expression," Frontiers in Physiology, vol. 8, p. 782, 2017.

[32] J. M. Sallenave and L. Guillot, "Innate immune signaling and proteolytic pathways in the resolution or exacerbation of SARS-CoV-2 in Covid-19: key therapeutic targets?," Frontiers in Immunology, vol. 11, p. 1229, 2020.

[33] Y. H. Chen, X. Teng, Z. J. Hu, D. Y. Tian, S. Jin, and Y. M. $\mathrm{Wu}$, "Hydrogen sulfide attenuated sepsis-induced myocardial dysfunction through TLR4 pathway and endoplasmic reticulum stress," Frontiers in Physiology, vol. 12, p. 653601, 2021.

[34] H. Li, Y. Ma, O. Escaffre et al., "Role of hydrogen sulfide in paramyxovirus infections," Journal of Virology, vol. 89, no. 10, pp. 5557-5568, 2015.

[35] Z. Varga, A. J. Flammer, P. Steiger et al., "Endothelial cell infection and endotheliitis in COVID-19," Lancet, vol. 395, no. 10234, pp. 1417-1418, 2020.

[36] T. C. Hanff, A. M. Mohareb, J. Giri, J. B. Cohen, and J. A. Chirinos, "Thrombosis in COVID-19," American Journal of Hematology, vol. 95, no. 12, pp. 1578-1589, 2020.

[37] Y. J. Peng, J. Nanduri, G. Raghuraman et al., " $\mathrm{H}_{2} \mathrm{~S}$ mediates $\mathrm{O}_{2}$ sensing in the carotid body," Proceedings of the National Academy of Sciences of the United States of America, vol. 107, no. 23, pp. 10719-10724, 2010.

[38] Y. R. Qin, S. J. You, Y. Zhang et al., "Hydrogen sulfide attenuates ferric chloride-induced arterial thrombosis in rats," Free Radical Research, vol. 50, no. 6, pp. 654-665, 2016.

[39] M. J. Wang, W. J. Cai, N. Li, Y. J. Ding, Y. Chen, and Y. C. Zhu, "The hydrogen sulfide donor NaHS promotes angiogenesis in a rat model of hind limb ischemia," Antioxidants \& Redox Signaling, vol. 12, no. 9, pp. 1065-1077, 2010.

[40] A. Porzionato, A. Emmi, S. Barbon et al., "Sympathetic activation: a potential link between comorbidities and COVID19,” The FEBS Journal, vol. 287, no. 17, pp. 3681-3688, 2020.

[41] X. C. Duan, R. Guo, S. Y. Liu et al., "Gene transfer of cystathionine $\beta$-synthase into RVLM increases hydrogen sulfidemediated suppression of sympathetic outflow via KATP channel in normotensive rats," American Journal of Physiology. Heart and Circulatory Physiology, vol. 308, no. 6, pp. H603-H611, 2015. 
[42] Y. F. Liang, D. D. Zhang, X. J. Yu et al., "Hydrogen sulfide in paraventricular nucleus attenuates blood pressure by regulating oxidative stress and inflammatory cytokines in high saltinduced hypertension," Toxicology Letters, vol. 270, pp. 6271, 2017.

[43] J. Lan, J. Ge, J. Yu et al., "Structure of the SARS-CoV-2 spike receptor-binding domain bound to the ACE2 receptor," Nature, vol. 581, no. 7807, pp. 215-220, 2020.

[44] D. Giustarini, A. Santucci, D. Bartolini, F. Galli, and R. Rossi, "The age-dependent decline of the extracellular thioldisulfide balance and its role in SARS-CoV-2 infection," Redox Biology, vol. 41, p. 101902, 2021.

[45] S. Hati and S. Bhattacharyya, "Impact of thiol-disulfide balance on the binding of Covid-19 spike protein with angiotensin-converting enzyme 2 receptor," ACS Omega, vol. 5, no. 26, pp. 16292-16298, 2020.

[46] M. Manček-Keber, I. Hafner-Bratkovič, D. Lainšček et al., "Disruption of disulfides within RBD of SARS-CoV-2 spike protein prevents fusion and represents a target for viral entry inhibition by registered drugs," The FASEB Journal, vol. 35, no. 6, article e21651, 2021.

[47] B. B. Tao, S. Y. Liu, C. C. Zhang et al., "VEGFR2 functions as an $\mathrm{H}_{2} \mathrm{~S}$-targeting receptor protein kinase with its novel Cys1045-Cys1024 disulfide bond serving as a specific molecular switch for hydrogen sulfide actions in vascular endothelial cells," Antioxidants \& Redox Signaling, vol. 19, no. 5, pp. 448-464, 2013.

[48] S. N. Ge, M. M. Zhao, D. D. Wu et al., "Hydrogen sulfide targets EGFR Cys797/Cys798 residues to induce $\mathrm{Na}(+) / \mathrm{K}(+)$ ATPase endocytosis and inhibition in renal tubular epithelial cells and increase sodium excretion in chronic salt-loaded rats," Antioxidants \& Redox Signaling, vol. 21, no. 15, pp. 2061-2082, 2014.

[49] M. Costantino, E. Lampa, and G. Nappi, "Effectiveness of sulphur spa therapy with politzer in the treatment of rhinogenic deafness," Acta Otorhinolaryngologica Italica, vol. 26, no. 1, pp. 7-13, 2006.

[50] R. Yang, X. Teng, H. Li et al., "Hydrogen sulfide improves vascular calcification in rats by inhibiting endoplasmic reticulum stress," Oxidative Medicine and Cellular Longevity, vol. 2016, 2016.

[51] J. Yi, Y. Yuan, J. Zheng, and N. Hu, "Hydrogen sulfide alleviates uranium-induced kidney cell apoptosis mediated by ER stress via $20 \mathrm{~S}$ proteasome involving in Akt/GSK-3 $\beta /$ FynNrf2 signaling," Free Radical Research, vol. 52, no. 9, pp. 1020-1029, 2018.

[52] H. Wei, R. Zhang, H. Jin et al., "Hydrogen sulfide attenuates hyperhomocysteinemia-induced cardiomyocytic endoplasmic reticulum stress in rats," Antioxidants \& Redox Signaling, vol. 12, no. 9, pp. 1079-1091, 2010.

[53] F. Lin, C. Liao, Y. Sun et al., "Hydrogen sulfide inhibits cigarette smoke-induced endoplasmic reticulum stress and apoptosis in bronchial epithelial cells," Frontiers in Pharmacology, vol. 8, p. 675, 2017.

[54] F. Okazaki, N. Matsunaga, H. Okazaki et al., "Circadian rhythm of transferrin receptor 1 gene expression controlled by c-Myc in colon cancer-bearing mice," Cancer Research, vol. 70, no. 15, pp. 6238-6246, 2010.

[55] K. Song, F. Wang, Q. Li et al., "Hydrogen sulfide inhibits the renal fibrosis of obstructive nephropathy," Kidney International, vol. 85, no. 6, pp. 1318-1329, 2014.
[56] P. Dasgupta and S. B. Sengupta, "Role of diallyl disulfidemediated cleavage of c-Myc and Sp-1 in the regulation of telomerase activity in human lymphoma cell line U937," Nutrition, vol. 31, no. 7-8, pp. 1031-1037, 2015.

[57] G. Gao, J. Li, Y. Zhang, and Y. Z. Chang, "Cellular Iron metabolism and regulation," Advances in Experimental Medicine and Biology, vol. 1173, pp. 21-32, 2019.

[58] G. Cairo, S. Recalcati, A. Pietrangelo, and G. Minotti, "The iron regulatory proteins: targets and modulators of free radical reactions and oxidative damage1, 2," Free Radical Biology \& Medicine, vol. 32, no. 12, pp. 1237-1243, 2002.

[59] H. Kimura, "Signalling by hydrogen sulfide and polysulfides via protein S-sulfuration," British Journal of Pharmacology, vol. 177, no. 4, pp. 720-733, 2020.

[60] R. Beydoun, M. A. Hamood, D. M. Gomez Zubieta, and K. C. Kondapalli, "NHE9 Regulates Iron Mobilization at the BBB," The Journal of Biological Chemistry, vol. 292, no. 10, pp. 4293-4301, 2017.

[61] G. Mudduluru and H. Allgayer, "The human receptor tyrosine kinase Axl gene-promoter characterization and regulation of constitutive expression by $\mathrm{Sp} 1, \mathrm{Sp} 3$ and $\mathrm{CpG}$ methylation," Bioscience Reports, vol. 28, no. 3, pp. 161-176, 2008.

[62] G. Meng, Y. Xiao, Y. Ma et al., "Hydrogen sulfide regulates Krüppel-like factor 5 transcription activity via specificity protein $1 \mathrm{~S}$-sulfhydration at Cys664 to prevent myocardial hypertrophy," Journal of the American Heart Association, vol. 5, no. 9, article e004160, 2016.

[63] H. Zhu, Y. M. Jin, X. M. Lyu, L. M. Fan, and F. Wu, "Long noncoding RNA H19 regulates HIF- $1 \alpha / \mathrm{AXL}$ signaling through inhibiting miR-20b-5p in endometrial cancer," Cell Cycle, vol. 18, no. 19, pp. 2454-2464, 2019.

[64] B. Wu, H. Teng, G. Yang, L. Wu, and R. Wang, "Hydrogen sulfide inhibits the translational expression of hypoxiainducible factor- $1 \alpha$," British Journal of Pharmacology, vol. 167, no. 7, pp. 1492-1505, 2012.

[65] S. Kai, T. Tanaka, H. Daijo et al., "Hydrogen sulfide inhibits hypoxia- but not anoxia-induced hypoxia-inducible factor 1 activation in a von Hippel-Lindau- and mitochondriadependent manner," Antioxidants \& Redox Signaling, vol. 16, no. 3, pp. 203-216, 2012.

[66] C. A. Vaughan, S. Singh, B. Windle et al., "Gain-of-function activity of mutant p53 in lung cancer through up-regulation of receptor protein tyrosine kinase Axl," Genes \& Cancer, vol. 3, no. 7-8, pp. 491-502, 2012.

[67] E. C. Rios, F. G. Soriano, G. Olah, D. Gerö, B. Szczesny, and C. Szabo, "Hydrogen sulfide modulates chromatin remodeling and inflammatory mediator production in response to endotoxin, but does not play a role in the development of endotoxin tolerance," Journal of Inflammation, vol. 13, no. 1, p. 10, 2016.

[68] T. M. Leucker, Y. Nomura, J. H. Kim et al., "Cystathionine $\gamma$ lyase protects vascular endothelium: a role for inhibition of histone deacetylase 6," American Journal of Physiology. Heart and Circulatory Physiology, vol. 312, no. 4, pp. H711-H720, 2017.

[69] A. K. Ajay, T. M. Kim, V. Ramirez-Gonzalez, P. J. Park, D. A. Frank, and V. S. Vaidya, "A bioinformatics approach identifies signal transducer and activator of transcription-3 and checkpoint kinase 1 as upstream regulators of kidney injury molecule-1 after kidney injury," Journal of the American Society of Nephrology, vol. 25, no. 1, pp. 105-118, 2014. 
[70] D. Tian, X. Teng, S. Jin et al., "Endogenous hydrogen sulfide improves vascular remodeling through PPAR $\delta / S O C S 3$ signaling," Journal of Advanced Research, vol. 27, pp. 115-125, 2020.

[71] M. Wang, H. Xin, W. Tang et al., "AMPK serves as a therapeutic target against anemia of inflammation," Antioxidants \& Redox Signaling, vol. 27, no. 5, pp. 251-268, 2017.

[72] H. J. Sun, S. P. Xiong, X. Cao et al., "Polysulfide-mediated sulfhydration of SIRT1 prevents diabetic nephropathy by suppressing phosphorylation and acetylation of p65 NF- $\kappa \mathrm{B}$ and STAT3," Redox Biology, vol. 38, p. 101813, 2021.

[73] J. Zuo, A. Khan, P. A. Glenton, and S. R. Khan, "Effect of $\mathrm{NADPH}$ oxidase inhibition on the expression of kidney injury molecule and calcium oxalate crystal deposition in hydroxy-L-proline-induced hyperoxaluria in the male Sprague-Dawley rats," Nephrology, Dialysis, Transplantation, vol. 26, no. 6, pp. 1785-1796, 2011.

[74] J. B. Collier and R. G. Schnellmann, "Extracellular signalregulated kinase $1 / 2$ regulates mouse kidney injury molecule-1 expression physiologically and following ischemic and septic renal injury," The Journal of Pharmacology and Experimental Therapeutics, vol. 363, no. 3, pp. 419-427, 2017.

[75] C. T. Yang, L. Chen, W. L. Chen et al., "Hydrogen sulfide primes diabetic wound to close through inhibition of NETosis," Molecular and Cellular Endocrinology, vol. 480, pp. 7482, 2019.

[76] M. Rossignol, J. Pouysségur, and M. Klagsbrun, "Characterization of the neuropilin-1 promoter; gene expression is mediated by the transcription factor Sp1," Journal of Cellular Biochemistry, vol. 88, no. 4, pp. 744-757, 2003.

[77] K. Brusselmans, F. Bono, D. Collen, J. M. Herbert, P. Carmeliet, and M. Dewerchin, "A novel role for vascular endothelial growth factor as an autocrine survival factor for embryonic stem cells during hypoxia," The Journal of Biological Chemistry, vol. 280, no. 5, pp. 3493-3499, 2005.

[78] E. Giraudo, L. Primo, E. Audero et al., “Tumor necrosis factor- $\alpha$ regulates expression of vascular endothelial growth factor receptor- 2 and of its co-receptor neuropilin-1 in human vascular endothelial cells," The Journal of Biological Chemistry, vol. 273, no. 34, pp. 22128-22135, 1998.

[79] J. M. Weiss, A. M. Bilate, M. Gobert et al., "Neuropilin 1 is expressed on thymus-derived natural regulatory $\mathrm{T}$ cells, but not mucosa-generated induced Foxp3+ T reg cells," The Journal of Experimental Medicine, vol. 209, no. 10, pp. 1723-1742, 2012, S1.

[80] B. E. Aboulhoda, L. A. Rashed, H. Ahmed et al., "Hydrogen sulfide and mesenchymal stem cells-extracted microvesicles attenuate LPS-induced Alzheimer's disease," Journal of Cellular Physiology, vol. 236, no. 8, pp. 5994-6010, 2021.

[81] B. H. Tran, Y. Yu, L. Chang et al., "A novel liposomal S-propargyl-cysteine: a sustained release of hydrogen sulfide reducing myocardial fibrosis via TGF- $\beta 1 /$ Smad pathway," International Journal of Nanomedicine, vol. Volume 14, pp. 10061-10077, 2019.

[82] W. Liu, T. Wu, X. Dong, and Y. A. Zeng, "Neuropilin-1 is upregulated by $\mathrm{Wnt} / \beta$-catenin signaling and is important for mammary stem cells," Scientific Reports, vol. 7, no. 1, p. 10941, 2017.

[83] H. L. Goel, B. Pursell, C. Chang et al., "GLI1 regulates a novel neuropilin-2/ $\alpha 6 \beta 1$ integrin based autocrine pathway that contributes to breast cancer initiation," EMBO Molecular Medicine, vol. 5, no. 4, pp. 488-508, 2013.

[84] X. Li, Y. Meng, C. Xie et al., "Diallyl trisulfide inhibits breast cancer stem cells via suppression of Wnt/ $\beta$-catenin pathway," Journal of Cellular Biochemistry, vol. 119, no. 5, pp. 41344141, 2018.

[85] S. H. Li, J. Fu, D. N. Watkins, R. K. Srivastava, and S. Shankar, "Sulforaphane regulates self-renewal of pancreatic cancer stem cells through the modulation of sonic hedgehog-GLI pathway," Molecular and Cellular Biochemistry, vol. 373, no. 1-2, pp. 217-227, 2013.

[86] L. Lubbe, G. E. Cozier, D. Oosthuizen, K. R. Acharya, and E. D. Sturrock, "ACE2 and ACE: structure-based insights into mechanism, regulation and receptor recognition by SARSCoV," Clinical Science (London, England), vol. 134, no. 21, pp. 2851-2871, 2020.

[87] K. Kuba, Y. Imai, T. Ohto-Nakanishi, and J. M. Penninger, "Trilogy of ACE2: a peptidase in the renin-angiotensin system, a SARS receptor, and a partner for amino acid transporters," Pharmacology \& Therapeutics, vol. 128, no. 1, pp. 119-128, 2010.

[88] R. Yan, Y. Zhang, Y. Li, L. Xia, Y. Guo, and Q. Zhou, "Structural basis for the recognition of SARS-CoV-2 by full-length human ACE2," Science, vol. 367, no. 6485, pp. 1444-1448, 2020 .

[89] D. Wrapp, N. Wang, K. S. Corbett et al., "Cryo-EM structure of the 2019-nCoV spike in the prefusion conformation," Science, vol. 367, no. 6483, pp. 1260-1263, 2020.

[90] K. F. R. Pobre, G. J. Poet, and L. M. Hendershot, "The endoplasmic reticulum (ER) chaperone $\mathrm{BiP}$ is a master regulator of ER functions: getting by with a little help from ERdj friends," The Journal of Biological Chemistry, vol. 294, no. 6, pp. 2098-2108, 2019.

[91] M. Gonzalez-Gronow, M. A. Selim, J. Papalas, and S. V. Pizzo, "GRP78: a multifunctional receptor on the cell surface," Antioxidants \& Redox Signaling, vol. 11, no. 9, pp. 2299-2306, 2009.

[92] M. Gonzalez-Gronow, U. Gopal, R. C. Austin, and S. V. Pizzo, "Glucose-regulated protein (GRP78) is an important cell surface receptor for viral invasion, cancers, and neurological disorders," IUBMB Life, vol. 73, no. 6, pp. 843-854, 2021.

[93] H. Chu, C. M. Chan, X. Zhang et al., "MERS-CoV and bCoV-HKU9 both utilize GRP78 for attachment," The Journal of Biological Chemistry, vol. 293, no. 30, pp. 1170911726, 2018.

[94] A. A. Elfiky, "SARS-CoV-2 spike-heat shock protein A5 (GRP78) recognition may be related to the immersed human coronaviruses," Frontiers in Pharmacology, vol. 11, p. 577467, 2020.

[95] A. A. Elfiky and I. M. Ibrahim, "Host-cell recognition through GRP78 is enhanced in the new UK variant of SARSCoV-2, _in silico_," The Journal of Infection, vol. 82, no. 5, pp. 186-230, 2021.

[96] A. Palmeira, E. Sousa, A. Köseler et al., "Preliminary virtual screening studies to identify GRP78 inhibitors which may interfere with SARS-CoV-2 infection," Pharmaceuticals (Basel), vol. 13, no. 6, p. 132, 2020.

[97] H. Kawabata, "Transferrin and transferrin receptors update," Free Radical Biology \& Medicine, vol. 133, pp. 46-54, 2019.

[98] Y. Shen, X. Li, D. Dong, B. Zhang, Y. Xue, and P. Shang, "Transferrin receptor 1 in cancer: a new sight for cancer 
therapy," American Journal of Cancer Research, vol. 8, no. 6, pp. 916-931, 2018.

[99] H. Drakesmith and A. Prentice, "Viral infection and iron metabolism," Nature Reviews Microbiology, vol. 6, no. 7, pp. 541-552, 2008.

[100] S. R. Radoshitzky, J. Abraham, C. F. Spiropoulou et al., "Transferrin receptor 1 is a cellular receptor for New World haemorrhagic fever arenaviruses," Nature, vol. 446, no. 7131, pp. 92-96, 2007.

[101] Y. Zhang, J. Gao, W. Sun et al., "H2S restores the cardioprotective effects of ischemic post-conditioning by upregulating HB-EGF/EGFR signaling," Aging (Albany NY), vol. 11, no. 6, pp. 1745-1758, 2019.

[102] L. F. Hu, Y. Li, K. L. Neo et al., "Hydrogen sulfide regulates $\mathrm{Na}+/ \mathrm{H}+$ Exchanger activity via stimulation of phosphoinositide 3-kinase/Akt and protein kinase G pathways," The Journal of Pharmacology and Experimental Therapeutics, vol. 339, no. 2, pp. 726-735, 2011.

[103] V. A. Korshunov, "Axl-dependent signalling: a clinical update," Clinical Science (London, England), vol. 122, no. 8, pp. 361-368, 2012.

[104] M. Tanaka and D. W. Siemann, "Gas6/Axl signaling pathway in the tumor immune microenvironment," Cancers, vol. 12, no. 7, p. 1850, 2020.

[105] L. Zhang, A. S. Richard, C. B. Jackson, A. Ojha, and H. Choe, "Phosphatidylethanolamine and phosphatidylserine synergize to enhance GAS6/AXL-mediated virus infection and efferocytosis," Journal of Virology, vol. 95, no. 2, article e02079, 2020.

[106] M. Bouhaddou, D. Memon, B. Meyer et al., "The global phosphorylation landscape of SARS-CoV-2 infection," Cell, vol. 182, no. 3, pp. 685-712.e19, 2020.

[107] A. Tutusaus, M. Marí, J. T. Ortiz-Pérez, G. A. F. Nicolaes, A. Morales, and P. García de Frutos, "Role of vitamin Kdependent factors protein S and GAS6 and TAM receptors in SARS-CoV-2 infection and COVID-19-associated immunothrombosis," Cells, vol. 9, no. 10, p. 2186, 2020.

[108] Z. Huang, X. Zhuang, C. Xie et al., "Exogenous hydrogen sulfide attenuates high glucose-induced cardiotoxicity by inhibiting NLRP3 inflammasome activation by suppressing TLR4/NF- $\kappa$ B pathway in H9c2 cells," Cellular Physiology and Biochemistry, vol. 40, no. 6, pp. 1578-1590, 2016.

[109] G. Y. Zhang, D. Lu, S. F. Duan et al., "Hydrogen sulfide alleviates lipopolysaccharide-induced diaphragm dysfunction in rats by reducing apoptosis and inflammation through ROS/MAPK and TLR4/NF- $\kappa \mathrm{B}$ signaling pathways," Oxidative Medicine and Cellular Longevity, vol. 2018, 2018.

[110] T. Zhang, K. Ono, H. Tsutsuki et al., "Enhanced cellular polysulfides negatively regulate TLR4 signaling and mitigate lethal endotoxin shock," Cell Chemical Biology, vol. 26, no. 5, pp. 686-698.e4, 2019.

[111] M. A. Rahman, B. M. Cumming, K. W. Addicott et al., "Hydrogen sulfide dysregulates the immune response by suppressing central carbon metabolism to promote tuberculosis," Proceedings of the National Academy of Sciences of the United States of America, vol. 117, no. 12, pp. 6663-6674, 2020.

[112] I. Badi, L. Mancinelli, A. Polizzotto et al., "miR-34a promotes vascular smooth muscle cell calcification by downregulating SIRT1 (sirtuin 1) and AXL (AXL receptor tyrosine kinase)," Arteriosclerosis, Thrombosis, and Vascular Biology, vol. 38, no. 9, pp. 2079-2090, 2018.
[113] X. Xiao, B. Chen, X. Liu et al., "Diallyl disulfide suppresses SRC/Ras/ERK signaling-mediated proliferation and metastasis in human breast cancer by up-regulating miR-34a," PLoS One, vol. 9, no. 11, article e112720, 2014.

[114] J. Song, J. Yu, G. W. Prayogo et al., "Understanding kidney injury molecule 1: a novel immune factor in kidney pathophysiology," American Journal of Translational Research, vol. 11, no. 3, pp. 1219-1229, 2019.

[115] C. Yin and N. Wang, "Kidney injury molecule-1 in kidney disease," Renal Failure, vol. 38, no. 10, pp. 1567-1573, 2016.

[116] M. J. Vogel, J. Mustroph, S. T. Staudner et al., "Kidney injury molecule-1: potential biomarker of acute kidney injury and disease severity in patients with COVID-19," Journal of Nephrology, vol. 34, no. 4, pp. 1007-1018, 2021.

[117] Z. Chen, J. Hu, L. Liu et al., "SARS-CoV-2 causes acute kidney injury by directly infecting renal tubules," Frontiers in Cell and Development Biology, vol. 9, p. 664868, 2021.

[118] T. Ichimura, Y. Mori, P. Aschauer et al., "KIM-1/TIM-1 is a receptor for SARS-CoV-2 in lung and kidney," medRxiv, 2020.

[119] C. Yang, Y. Zhang, X. Zeng et al., "Kidney injury molecule-1 is a potential receptor for SARS-CoV-2," Journal of Molecular Cell Biology, vol. 13, no. 3, pp. 185-196, 2021.

[120] A. S. Papu John, S. Kundu, S. Pushpakumar, M. Amin, S. C. Tyagi, and U. Sen, "Hydrogen sulfide inhibits Ca2+-induced mitochondrial permeability transition pore opening in type1 diabetes," American Journal of Physiology. Endocrinology and Metabolism, vol. 317, no. 2, pp. E269-E283, 2019.

[121] G. J. Dugbartey, F. Talaei, M. C. Houwertjes et al., "Dopamine treatment attenuates acute kidney injury in a rat model of deep hypothermia and rewarming - the role of renal $\mathrm{H}_{2} \mathrm{~S}$ producing enzymes," European Journal of Pharmacology, vol. 769, pp. 225-233, 2015.

[122] H. F. Guo and C. W. Vander Kooi, "Neuropilin Functions as an Essential Cell Surface Receptor," The Journal of Biological Chemistry, vol. 290, no. 49, pp. 29120-29126, 2015.

[123] H. B. Wang, H. Zhang, J. P. Zhang et al., "Neuropilin 1 is an entry factor that promotes EBV infection of nasopharyngeal epithelial cells," Nature Communications, vol. 6, no. 1, p. $6240,2015$.

[124] S. Lambert, M. Bouttier, R. Vassy et al., "HTLV-1 uses HSPG and neuropilin-1 for entry by molecular mimicry of VEGF165," Blood, vol. 113, no. 21, pp. 5176-5185, 2009.

[125] R. K. Lane, H. Guo, A. D. Fisher et al., "Necroptosis-based CRISPR knockout screen reveals neuropilin-1 as a critical host factor for early stages of murine cytomegalovirus infection," Proceedings of the National Academy of Sciences of the United States of America, vol. 117, no. 33, pp. 20109-20116, 2020.

[126] L. Cantuti-Castelvetri, R. Ojha, L. D. Pedro et al., "Neuropilin-1 facilitates SARS-CoV-2 cell entry and infectivity," Science, vol. 370, no. 6518, pp. 856-860, 2020.

[127] E. Yagdi, C. Cerella, M. Dicato, and M. Diederich, "Garlicderived natural polysulfanes as hydrogen sulfide donors: friend or foe?," Food and Chemical Toxicology, vol. 95, pp. 219-233, 2016.

[128] T. Cui, W. Liu, S. Chen, C. Yu, Y. Li, and J. Y. Zhang, "Antihypertensive effects of allicin on spontaneously hypertensive rats via vasorelaxation and hydrogen sulfide mechanisms," Biomedicine \& Pharmacotherapy, vol. 128, p. $110240,2020$. 
[129] R. N. Carter and N. M. Morton, "Cysteine and hydrogen sulphide in the regulation of metabolism: insights from genetics and pharmacology," The Journal of Pathology, vol. 238, no. 2, pp. 321-332, 2016.

[130] D. M. Guizoni, I. N. Freitas, J. A. Victorio et al., "Taurine treatment reverses protein malnutrition-induced endothelial dysfunction of the pancreatic vasculature: the role of hydrogen sulfide," Metabolism, vol. 116, p. 154701, 2021.

[131] J. L. Wallace, P. Nagy, T. D. Feener et al., "A proof-of-concept, phase 2 clinical trial of the gastrointestinal safety of a hydrogen sulfide-releasing anti-inflammatory drug," British Journal of Pharmacology, vol. 177, no. 4, pp. 769-777, 2020.

[132] J. M. Paquette, M. Rufiange, M. Iovu Niculita et al., "Safety, tolerability and pharmacokinetics of trimebutine 3thiocarbamoylbenzenesulfonate (GIC-1001) in a randomized phase I integrated design study: single and multiple ascending doses and effect of food in healthy volunteers," Clinical Therapeutics, vol. 36, no. 11, pp. 1650-1664, 2014.

[133] X. Qiu, K. Liu, L. Xiao et al., "Alpha-lipoic acid regulates the autophagy of vascular smooth muscle cells in diabetes by elevating hydrogen sulfide level," Biochimica et Biophysica Acta - Molecular Basis of Disease, vol. 1864, no. 11, pp. 3723-3738, 2018.

[134] F. Terstappen, S. M. Clarke, J. A. Joles et al., "Sodium thiosulfate in the pregnant Dahl salt-sensitive rat, a model of preeclampsia," Biomolecules, vol. 10, no. 2, p. 302, 2020.

[135] M. Bucci, V. Vellecco, A. Cantalupo et al., "Hydrogen sulfide accounts for the peripheral vascular effects of zofenopril independently of ACE inhibition," Cardiovascular Research, vol. 102, no. 1, pp. 138-147, 2014.

[136] C. N. Hsu, C. Y. Hou, G. P. Chang-Chien, S. Lin, and Y. L. Tain, "Maternal N-acetylcysteine therapy prevents hypertension in spontaneously hypertensive rat offspring: implications of hydrogen sulfide-generating pathway and gut microbiota," Antioxidants, vol. 9, no. 9, p. 856, 2020.

[137] M. B. Evgen'ev and A. Frenkel, "Possible application of H2Sproducing compounds in therapy of coronavirus (COVID19) infection and pneumonia," Cell Stress \& Chaperones, vol. 25, no. 5, pp. 713-715, 2020. 